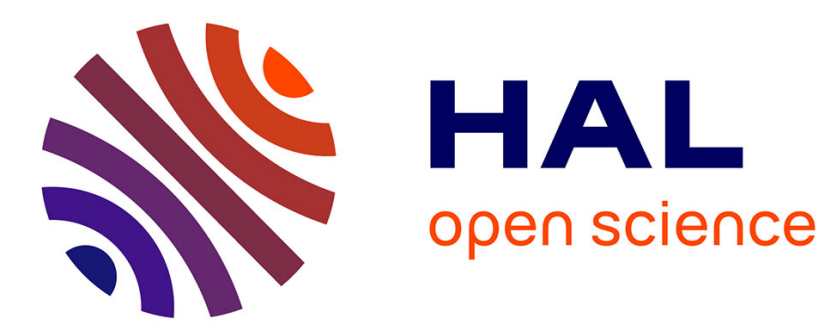

\title{
Impacts métaboliques et inflammatoires des matières grasses émulsionnées
}

Marie-Caroline Michalski, Cécile Vors, Manon Lecomte, Fabienne Laugerette

\section{To cite this version:}

Marie-Caroline Michalski, Cécile Vors, Manon Lecomte, Fabienne Laugerette. Impacts métaboliques et inflammatoires des matières grasses émulsionnées. OCL Oilseeds and fats crops and lipids, 2017, 24 (2), pp.12. 10.1051/ocl/2017009 . hal-01848137

\section{HAL Id: hal-01848137 \\ https://hal.science/hal-01848137}

Submitted on 25 May 2020

HAL is a multi-disciplinary open access archive for the deposit and dissemination of scientific research documents, whether they are published or not. The documents may come from teaching and research institutions in France or abroad, or from public or private research centers.
L'archive ouverte pluridisciplinaire HAL, est destinée au dépôt et à la diffusion de documents scientifiques de niveau recherche, publiés ou non, émanant des établissements d'enseignement et de recherche français ou étrangers, des laboratoires publics ou privés.

\section{다(1)(2)}

Distributed under a Creative Commons Attribution - ShareAlikel 4.0 International 


\title{
Impacts métaboliques et inflammatoires des matières grasses émulsionnées
}

\author{
Marie-Caroline Michalski ${ }^{1,2, *}$, Cécile Vors ${ }^{1,2}$, Manon Lecomte ${ }^{1,2}$ et Fabienne Laugerette ${ }^{1,2}$ \\ ${ }^{1}$ Université de Lyon, laboratoire CarMeN, INRA, UMR 1397, INSERM, U1060, université Claude-Bernard - Lyon 1, INSA-Lyon, \\ bâtiment IMBL, 15, avenue Jean-Capelle, 69621 Villeurbanne cedex, France \\ 2 CRNH Rhône-Alpes, CENS, 69310 Pierre-Bénite, France
}

Reçu le 31 janvier 2017 - Accepté le 2 mars 2017

\begin{abstract}
Résumé - Les effets des lipides sur la santé doivent aujourd'hui être étudiés par des approches allant au-delà de leur densité énergétique et de leur profil en acides gras. En effet, ces acides gras sont les briques élémentaires de différentes molécules lipidiques telles que les triacylglycérols et les phospholipides, elles-mêmes organisées sous forme de structures supramoléculaires variées comme les gouttelettes d'émulsion, et pouvant être intégrées dans différentes matrices alimentaires. Ce court article résume nos récents travaux sur l'impact de l'état émulsionné de la matière grasse sur le métabolisme post-prandial des lipides et la $\beta$-oxydation des acides gras ingérés chez l'homme mince ou obèse, ouvrant la voie au concept de «lipides rapides versus lipides lents ». Nous présentons comment la cinétique post-prandiale d'absorption des lipides peut aussi contribuer à moduler l'endotoxémie métabolique, provenant en partie d'interactions entre les lipides alimentaires et le microbiote intestinal et pouvant contribuer à l'inflammation métabolique chez l'obèse. Enfin, nous mettons en exergue l'impact pro- ou anti-inflammatoire chez la souris d'agents tensioactifs utilisés en formulation alimentaire pour stabiliser les émulsions, notamment les phospholipides d'origine végétale ou laitière, ainsi que de différents vecteurs moléculaires d'acides gras poly-insaturés n-3 à longue chaîne. Le lecteur pourra se référer à nos autres publications et revues récentes pour un approfondissement des concepts présentés.
\end{abstract}

Mots clés : nutrition / matière grasse / huile / émulsifiant / inflammation / oxydation / phospholipide

\begin{abstract}
Metabolic and inflammatory impacts of emulsified fat. The health effects of lipids must now be explored beyond their energy content and fatty acid profile. Indeed, fatty acids as unit elements of different molecules such as triacylglycerols and phospholipids are being organized in various supramolecular structures such as emulsion droplets, and incorporated in complex food matrixes. This short article reviews our recent studies on the impact of fat emulsified structure on postprandial lipid metabolism and fatty acid beta-oxidation in normal-weight and obese humans, leading to the concept of "fast versus slow lipids". We also show how the postprandial kinetics of lipid absorption can contribute to modulate metabolic endotoxemia, partly arising from interactions between dietary lipids and gut microbiota, and able to contribute to metabolic inflammation in obesity. Finally, we highlight the pro- or antiinflammatory impact in mice of surface active agents used in food formulation to stabilize emulsions, notably phospholipids of vegetal or dairy origin, and different molecular carriers of long-chain n-3 polyunsaturated fatty acids. The interested reader will refer to our other recent publications and reviews on these topics for a deeper insight into presented concepts.
\end{abstract}

Keywords: nutrition / fat / oil / emulsifier / inflammation / oxidation / phospholipid

\section{Introduction}

L'absorption intestinale des nutriments et les évènements métaboliques durant la période post-prandiale jouent un rôle

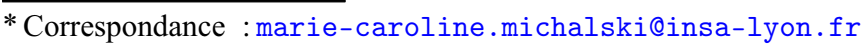

majeur dans l'initiation et le développement des maladies métaboliques et cardiovasculaires. Le métabolisme postprandial des lipides fait l'objet de nombreuses recherches afin de comprendre comment mieux contrôler le devenir des lipides ingérés. De nombreuses études ont en effet mis en exergue que l'augmentation de la quantité de lipides ingérés favorisait l'augmentation des paramètres lipidiques sanguins. 


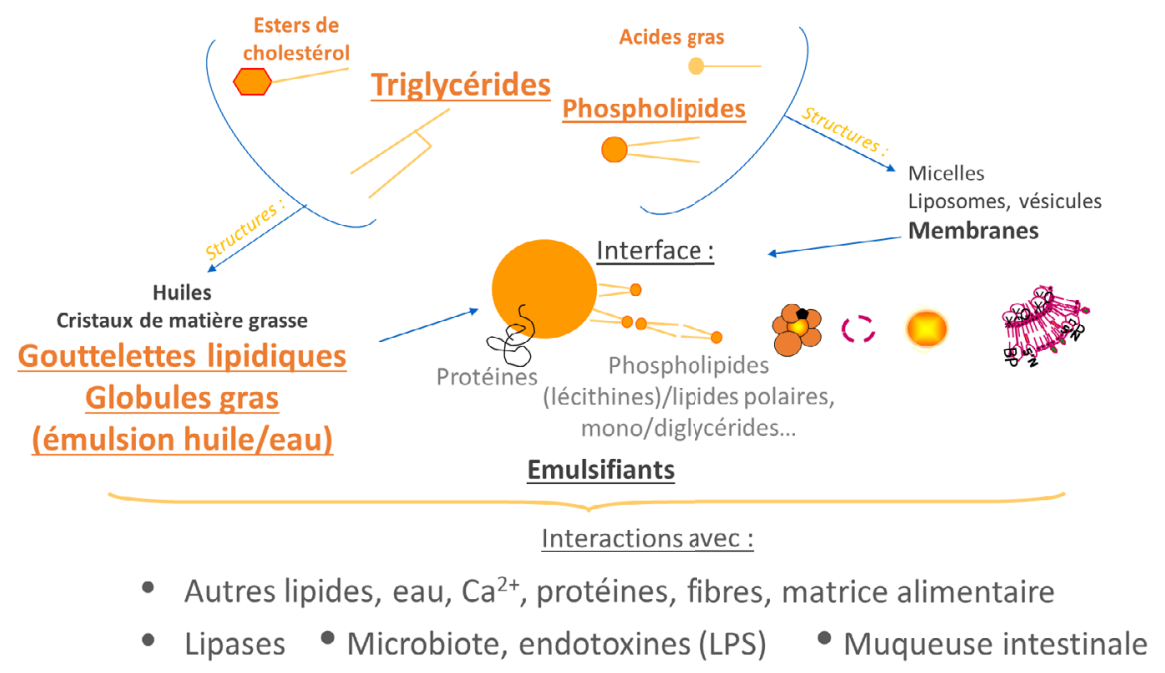

Fig. 1. Exemples d'organisations supramoléculaires des molécules lipidiques dans les aliments, d'émulsions huile-dans-eau et agents émulsifiants, pouvant impacter les phénomènes digestifs et postprandiaux. Source : adapté de Michalski et al. (2013).

Or, une hypertriglycéridémie prolongée est associée à un risque cardiovasculaire accru (Nordestgaard et al., 2007). De plus, la capacité à augmenter l'oxydation lipidique en réponse à un apport lipidique est généralement réduite et l'obésité est associée à un défaut de la $\beta$-oxydation lipidique ainsi qu'à une distribution des lipides alimentaires favorisant leur stockage. Ainsi, un meilleur contrôle de l'absorption des lipides et de leur répartition post-prandiale via une clairance efficace de la lipémie, associée à une $\beta$-oxydation lipidique importante, est l'un des enjeux actuels de la recherche en nutrition (Laville et al., 2013).

Dans ce contexte, les effets métaboliques de la qualité et de la quantité de lipides ingérés ont été largement étudiés mais ceux dépendant directement de la structure des lipides alimentaires sont un domaine émergent de recherche. Les lipides ne sont en effet que rarement consommés en l'état ; ils sont une partie constitutive des aliments et même s'ils peuvent conserver leur organisation native, ils se réorganisent généralement en fonction des autres constituants présents et des traitements technologiques appliqués au cours de la formulation ou de la préparation. Ainsi, dans les aliments transformés, à l'échelle macroscopique, une grande diversité d'organisations ou de structures de lipides existe dans les aliments (Fig. 1) :

- sous forme libre, en phase continue homogène (cas des huiles) ;

- sous forme de gouttelettes d'émulsion huile-dans-eau (cas des sauces vinaigrettes et mayonnaises, lait, ou encore des yaourts qui sont des émulsions gélifiées) ;

- sous forme de phase continue d'une émulsion eau-danshuile (beurre, margarine) ;

- sous forme d'inclusions lipidiques dans des matrices solides glucidiques ou protéiques (cas des produits élaborés tels que les biscuits et les fromages).

Parmi les différents niveaux de structure des lipides, la forme émulsionnée est la plus répandue dans l'alimentation et correspond constitutivement à certaines structures naturelles comme celle des globules gras du lait. Les récentes avancées de la recherche en nutrition que nous soulignerons ont permis de mettre en évidence que la structuration moléculaire et supramoléculaire de la matière grasse dans les aliments, et notamment sa structure émulsionnée, module sa digestion et la biodisponibilité des acides gras (Michalski, 2009 ; RaynalLjutovak et al., 2011 ; Michalski et al., 2013).

Ce court article résume nos récents travaux sur l'impact de l'état émulsionné de la matière grasse sur le métabolisme postprandial des lipides et la $\beta$-oxydation des acides gras ingérés chez l'homme mince ou obèse, ouvrant la voie au concept de " lipides rapides versus lipides lents ». Nous présentons comment la cinétique post-prandiale d'absorption des lipides peut aussi contribuer à moduler l'endotoxémie métabolique, provenant en partie d'interactions entre les lipides alimentaires et le microbiote intestinal et pouvant contribuer à l'inflammation métabolique chez l'obèse. Enfin, nous mettons en exergue l'impact d'agents tensioactifs utilisés en formulation alimentaire pour stabiliser les émulsions, notamment les phospholipides d'origine végétale ou laitière, ainsi que de différents vecteurs moléculaires d'acides gras poly-insaturés n-3 à longue chaîne. Le lecteur pourra se référer à nos autres publications et revues récentes sur ces thématiques (Bourlieu et Michalski, 2015 ; Genot et al., 2016 ; Michalski et al., 2016 ; Vors et al., 2016) pour un accès plus exhaustif aux références bibliographiques et un approfondissement des concepts présentés.

\section{La structure émulsionnée des lipides a des conséquences sur la digestion et l'absorption : le concept des "lipides rapides versus lents "}

Nos travaux ont tout d'abord approfondi les démonstrations in vivo que la dispersion des lipides sous la forme de gouttelettes d'émulsion peut affecter l'absorption intestinale et ainsi modifier la cinétique finale de lipémie post-prandiale, c'est-à-dire la quantité de triglycérides circulant dans le plasma sanguin suite au repas. Chez le rat, des globules gras du lait homogénéisés ou non et des gouttelettes d'émulsion de matière grasse laitière recouvertes de protéines ou de phospholipides 
n'aboutissent pas à la même cinétique de lipémie au cours de la période de digestion (Michalski et al., 2005, 2006). Des réponses de moindre amplitude ont en effet été observées pour les globules homogénéisés par rapport aux globules gras natifs, et pour les gouttelettes recouvertes de caséines par rapport à de la lécithine. Concernant des huiles végétales, toujours chez le rat, administrer l'huile de lin sous forme émulsionnée avec de la lécithine de soja aboutit à une absorption lymphatique des acides gras supérieure à celle obtenue avec l'huile non émulsionnée, démontrant une augmentation de l'absorption intestinale (Couedelo et al., 2011, 2015). Cela aboutit à une augmentation globale de la lipémie postprandiale, comme montré chez le rat après administration d'huile de tournesol émulsionnée ou non avec le même type de lécithine (Laugerette et al., 2011a). Enfin, notre récente collaboration avec nos partenaires de l'Institut des corps gras (ITERG) montre que chez le rat, l'absorption intestinale et la sécrétion lymphatique de l'acide alpha-linolénique (ALA) sont augmentées suite à l'utilisation de lécithine de soja versus caséinate de sodium pour stabiliser une huile de lin émulsionnée (Couedelo et al., 2015).

Peu de données étaient cependant disponibles chez l'homme. Lorsque des sujets sains consomment une huile riche en acides gras poly-insaturés, pré-émulsionnée ou non, les cinétiques de lipémie obtenues pour les deux formes ingérées sont très différentes. Au bout de neuf heures, une absorption plus importante des acides gras poly-insaturés est en effet observée lorsqu'ils ont été préalablement émulsionnés (Garaiova et al., 2007). La nature des émulsifiants peut aussi avoir une influence : des émulsions stabilisées par des caséines et des monoglycérides induisent une lipémie post-prandiale plus faible, comparées à celles stabilisées avec des phospholipides (lécithine d'œuf) (Keogh et al., 2011). Cependant, une autre étude montre qu'une fois les lipides émulsionnés dans un mélange de protéines et de phospholipides, la taille des gouttelettes d'émulsion $(\sim 1 \mu \mathrm{m}$ versus $\sim 10 \mu \mathrm{m})$ n'affecte pas fortement la cinétique de lipémie post-prandiale (Armand et al., 1999).

Ainsi, les études publiées à ce jour ont clairement démontré l'impact de la structuration de la matière grasse sur l'absorption lipidique et la lipémie qui en résulte sans pour autant suivre finement le devenir métabolique final des acides gras après leur absorption intestinale. Or, chez le rongeur, nous avons montré que différentes structures émulsionnées induisent différentes cinétiques de $\beta$-oxydation finale des acides gras chez le rat (Michalski et al., 2005). L'ensemble de ces résultats nous a amené à tester, chez l'homme, l'hypothèse qu'au-delà de simples aspects cinétiques liés à une vitesse d'absorption plus ou moins rapide, l'utilisation des acides gras par l'organisme pourrait être modifiée par la structure d'apport de ces acides gras dans l'aliment.

Nous avons ainsi mis en place l'étude LIPINFLOX, preuve du concept que la structure supramoléculaire émulsionnée de la matière grasse dans le repas était de nature à moduler la cinétique de lipémie puis le devenir métabolique des lipides ingérés ( $\beta$-oxydation versus stockage) (Vors et al., 2013). Le but de l'étude était de montrer les contributions respectives de la structure émulsionnée de la matière grasse et de l'indice de masse corporelle des volontaires sur les caractéristiques du métabolisme lipidique post-prandial (Fig. 2) : lipémie et propriétés des chylomicrons, libération d'acides gras dans le

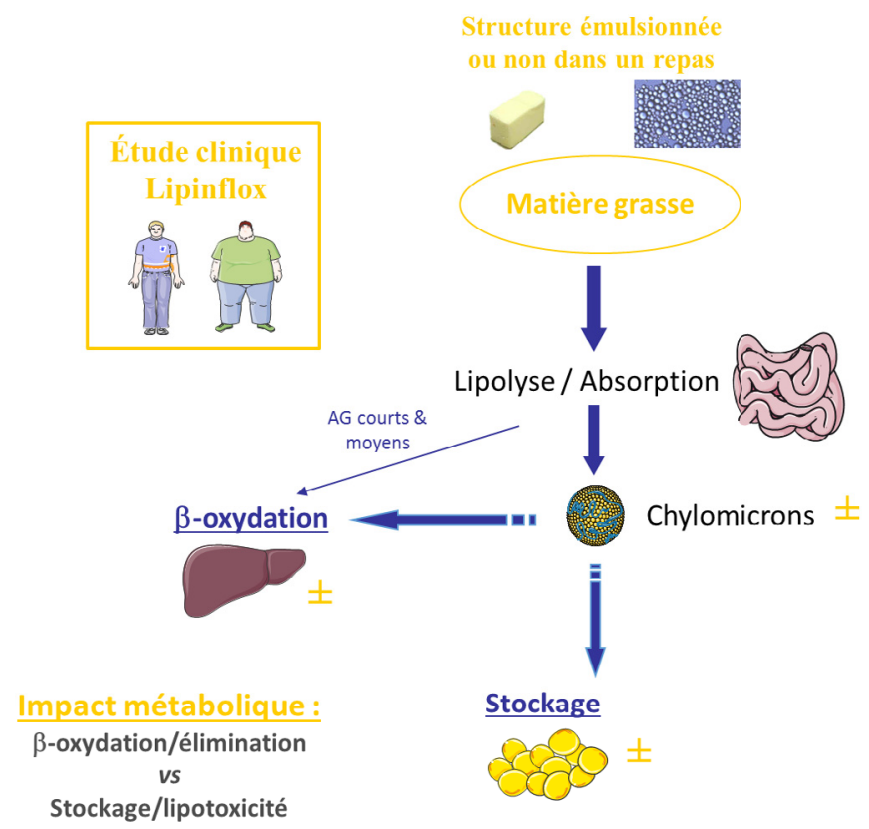

Fig. 2. Étude LIPINFLOX visant à montrer l'impact de la structure émulsionnée ou tartinée dans un repas sur le devenir métabolique des acides gras (Vors et al., 2013, 2016).

plasma, $\beta$-oxydation. L'étude LIPINFLOX révèle pour la première fois que la matière grasse laitière finement émulsionnée modifie le profil de cinétique des triglycérides des chylomicrons par rapport à la forme tartinée (non émulsionnée) : le pic de chylomicrons est plus précoce et plus prononcé mais aussi plus rapidement éliminé, en particulier chez les sujets obèses (Vors et al., 2013). Ceci prouve que des effets facilitants de l'émulsification sur la lipolyse et l'absorption peuvent être obtenus dans le cadre d'un repas mixte réaliste chez l'homme, alors que les études précédentes employaient une émulsion seule (Armand et al., 1999; Keogh et al., 2011), parfois même administrée par sonde nasogastrique (Armand et al., 1999). L'importance métabolique d'une modification du profil de lipémie ne doit pas être négligée. Une lipémie maintenue élevée en période post-prandiale, due en partie à une mauvaise clairance des chylomicrons, est en effet reconnue comme un facteur de risque indépendant de maladies cardiovasculaires (Nordestgaard et al., 2007 ; Langsted et Nordestgaard, 2015).

Un aspect novateur de l'étude LIPINFLOX a été de s'intéresser au devenir métabolique ultime des acides gras ingérés. Par un test respiratoire au ${ }^{13} \mathrm{C}$, nous avons pu démontrer une $\beta$-oxydation plus élevée des acides gras ingérés sous la forme émulsionnée : chez les sujets obèses, la $\beta$-oxydation est d'environ $60 \%$ versus $40 \%$ pour la forme non émulsionnée, sans différence de perte fécale (Michalski et Vors, 2013 ; Vors et al., 2013). Ces résultats sont cohérents avec l'observation d'un afflux d'acides gras non estérifiés dans le plasma (spillover) plus important suite à l'émulsion dans les deux groupes de volontaires. Ce débordement d'acides gras libres peut s'expliquer par une meilleure absorption intestinale des lipides émulsionnés, résultant en une lipolyse des chylomicrons plus précoce qui génère alors des acides gras circulants d'origine exogène. Ultimement, cet apport précoce et important d'acides gras libres circulants exogènes sert alors 
de substrat aux différents tissus périphériques et explique, dans le cas de l'émulsion, la contribution plus importante des acides gras exogènes à l'oxydation lipidique totale (Vors et al., 2013).

\section{Un phénomène pro-inflammatoire associé à l'absorption lipidique : l'endotoxémie post- prandiale}

Outre des troubles du métabolisme lipidique, les maladies métaboliques (obésité, diabète de type 2) sont caractérisées par la mise en place et le maintien d'un état inflammatoire à basbruit, qui augmente le risque cardiovasculaire (Ross, 1999 ; Libby, 2002). Un régime alimentaire déséquilibré et la période post-prandiale contribueraient à l'établissement de cette inflammation métabolique (Vors et al., 2014 ; Michalski et al., 2016). Ces dernières années des études ont révélé que des molécules pro-inflammatoires d'origine bactérienne, naturellement présentes dans le microbiote intestinal, peuvent gagner la circulation sanguine. Il s'agit des endotoxines (appellation biochimique : lipopolysaccharides [LPS]), dont la concentration plasmatique (endotoxémie) est augmentée chez des personnes obèses (Libby, 2002), des diabétiques de type 2 (Creely et al., 2007) et des patients atteints de la maladie de Crohn (Pastor Rojo et al., 2007). De plus, l'endotoxémie plasmatique a été reportée fortement corrélée aux différents composants du syndrome métabolique (Lassenius et al., 2011). Ces travaux ont ouvert la voie à un nouveau domaine de recherche sur l'importance du microbiote intestinal dans l'établissement et le maintien de l'inflammation à bas-bruit, notamment via la libération d'endotoxines.

Les endotoxines (LPS) représentent $80 \%$ de la paroi cellulaire des bactéries Gram négatif. Elles sont constituées d'une partie polysaccharidique, la chaîne $\mathrm{O}$ spécifique (antigène $\mathrm{O}$ ), et d'une partie lipidique, le lipide $\mathrm{A}$, région fortement conservée et représentant la partie toxique du LPS (Osborn et al., 1964). Dans la circulation sanguine, les LPS sont pris en charge par une protéine spécifique de transport : la lipopolysaccharide-binding protein (LBP, $60 \mathrm{kDa}$ ) produite par le foie et présente dans le plasma à des concentrations de 2 à $20 \mu \mathrm{g} / \mathrm{mL}$ (de l'ordre de $18 \mu \mathrm{g} / \mathrm{mL}$ chez l'homme) (Gallay et al., 1994). Les LPS sont ensuite transférés au récepteur CD14 (cluster of differentiation 14 ; Fig. 3), se présentant sous deux formes : une forme membranaire (mCD14) exprimée sur la membrane de nombreuses cellules (macrophages, monocytes...) (Hailman et al., 1994), et une forme soluble (sCD14) (Bazil et Strominger, 1991). LBP et sCD14 sont considérés comme des marqueurs de présence des endotoxines dans le plasma (Hiki et al., 1999), leurs demi-vies (24-48 heures) étant supérieures à celle des endotoxines (moins de huit minutes chez la souris et jusqu'à trois heures chez l'homme) (Pastor Rojo et al., 2007 ; Matsushita et al., 2010). De plus, le rapport LBP/sCD14 est augmenté lors de certaines maladies inflammatoires, telles que la maladie de Crohn (Lakatos et al., 2011). D'un point de vue métabolique, les deux formes de CD14 sont capables de lier le complexe LPS-LBP, qui se fixe alors sur le récepteur TLR4 (Toll-like receptor 4) et le co-récepteur MD2 (myeloid differentiation protein-2), puis de médier la transduction du signal via l'activation de NF-қB (nuclear factor- $\kappa B$ ). Cette cascade de signalisation résulte en la libération de cytokines pro-inflammatoires (IL-6, TNF- $\alpha$...)

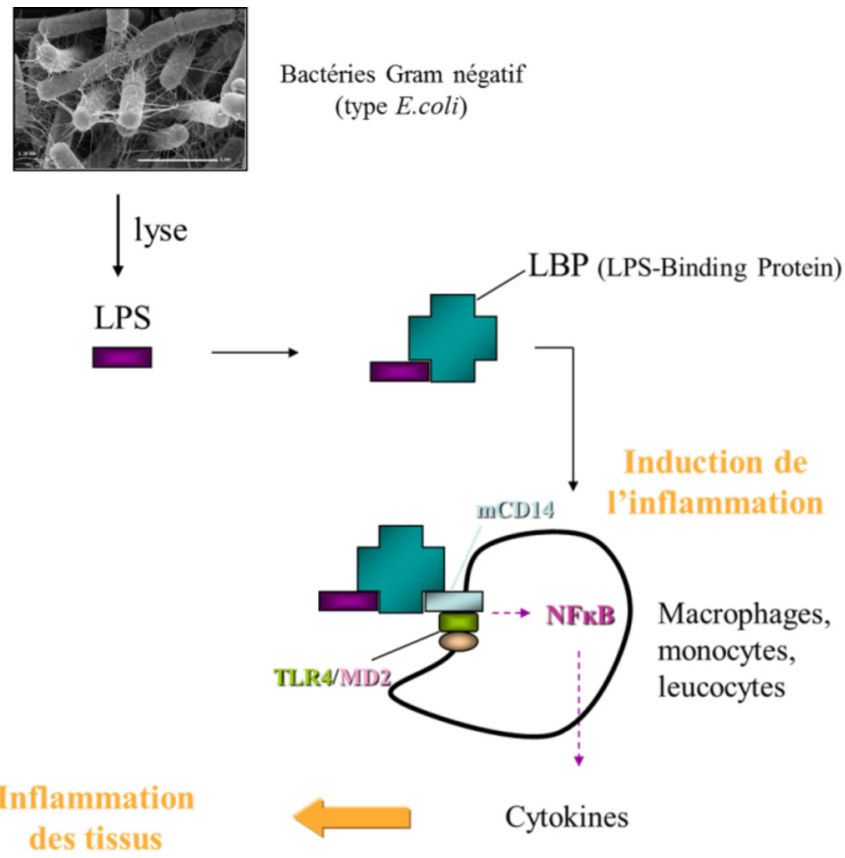

Fig. 3. Cascade pro-inflammatoire induite par les lipopolysaccharides (LPS). Les LPS sont transportés dans la circulation sanguine par une glycoprotéine spécifique, la lipopolysaccharide-binding protein (LBP), jusqu'aux cellules du système immunitaire (tels que les macrophages) et les activent via un complexe trimoléculaire composé $\mathrm{du}$ cluster of differentiation 14 (CD14), du Toll-like receptor 4 (TLR4) et de la myeloid differentiation protein-2 (MD2). Le CD14 sert de récepteur au complexe LPS/LBP et permet de le transférer vers TLR4 et MD2, engendrant ainsi une activation des voies de signalisation intracellulaires. Celles-ci provoquent alors la transcription de gènes, tel que nuclear factor $-\mathrm{K} B(\mathrm{NF}-\mathrm{KB})$, aboutissant à la synthèse de cytokines (IL-6, IL-1 $\beta$, TNF- $\alpha$, etc.) par les cellules immunitaires. Source : adapté de Laugerette et al. (2011a) et de Vors et al. (2014).

(Fig. 3). Lors de chocs septiques, la LBP peut transférer les LPS aux lipoprotéines plasmatiques (HDL, chylomicrons), ce qui permet la neutralisation de l'activité des endotoxines (Eichbaum et al., 1991 ; Harris et al., 1993 ; Vreugdenhil et al., 2003). Cette neutralisation résulte de la liaison des lipoprotéines à leurs récepteurs notamment dans le foie, induisant ensuite l'élimination des LPS par sécrétion biliaire (Eichbaum et al., 1991 ; Harris et al., 1993, 1998 ; Vreugdenhil et al., 2003). En plus de la LBP, la protéine de transfert des phospholipides (phospholipid transfer protein [PLTP]) peut lier les LPS et ainsi détoxifier l'organisme lors de chocs septiques (Gautier et al., 2008).

Cani et al. ont fait la preuve du concept qu'un régime hyperlipidique de quatre semaines chez la souris $(72 \%$ de l'énergie apportée par les lipides) augmente l'endotoxémie contrairement à un régime contrôle normolipidique. L'endotoxémie induite par ce régime hyperlipidique était 2,7 fois supérieures à celle observée suite au régime contrôle (Cani et al., 2007). En outre, une infusion chronique à faible dose de LPS, similaire à celle observée suite au régime hyperlipidique, conduit à une prise de poids et au développement de l'insulinorésistance chez des souris nourries d'un régime normolipidique. Cependant, des souris KO-CD14 (génétique- 
ment invalidées concernant le récepteur CD14) ne développent pas la prise de poids et l'insulinorésistance avec le régime hyperlipidique décrit précédemment, montrant ainsi l'importance de ce récepteur dans l'impact métabolique des endotoxines (Cani et al., 2007). De plus, l'augmentation plasmatique des LPS est moindre $(1,4$ fois par rapport au régime contrôle) quand les souris sont soumises à un régime contenant $40 \%$ d'énergie apportée par les lipides au lieu de $72 \%$ (Cani et al., 2007). Chez l'homme sain à risque cardiovasculaire, ces mêmes auteurs ont montré une corrélation positive entre la prise énergétique et l'endotoxémie (Amar et al., 2008). L'un des mécanismes observé chez la souris est une augmentation de perméabilité intestinale par une altération de la barrière intestinale au niveau du côlon, induisant une translocation paracellulaire d'endotoxines vers la circulation sanguine (Cani et al., 2008).

\subsection{L'endotoxémie post-prandiale est en partie liée aux chylomicrons chez l'homme}

Cependant, différents auteurs ont ensuite mis en évidence le rôle de la phase post-prandiale dans la mise en place de l'endotoxémie métabolique. Un mécanisme complémentaire serait donc lié à un passage paracellulaire de LPS au niveau de l'intestin grêle (Fig. 4). Une première étude chez l'homme a mis en évidence que chez des sujets minces à obèses, fumeurs occasionnels, un repas à base de toasts avec $50 \mathrm{~g}$ de beurre était suffisant pour augmenter de manière transitoire l'endotoxémie, 30 minutes après ingestion (Erridge et al., 2007). Chez la souris, 90 minutes après un gavage avec de la trioléine (triglycéride simple de l'acide oléique, C18:1n-9), l'endotoxémie plasmatique était augmentée contrairement à un gavage avec de la tributyrine (triglycéride simple de l'acide butyrique C4:0) qui n'induit pas de sécrétion de chylomicrons ou encore suite à un composé chimique bloquant la sécrétion des chylomicrons (Ghoshal et al., 2009). De plus, des études chez des hommes sains et minces ont montré une augmentation des LPS plasmatiques en période post-prandiale suite à l'ingestion de repas riches en graisses, avec ou sans glucides (Deopurkar et al., 2010 ; Ghanim et al., 2010). La cascade d'évènements liés aux transporteurs de LPS, le lien avec la chylomicronémie chez l'homme et l'impact de la composition des lipides ingérés restaient cependant à élucider.

Nos travaux ont montré chez l'homme sain non fumeur, normopondéré ou en surpoids, que la digestion d'un repas varié contenant $33 \mathrm{~g}$ de lipides de différentes sources $(23 \mathrm{~g}$ de margarine, $9 \mathrm{~g}$ de beurre et $1 \mathrm{~g}$ d'huile d'olive) entrainait une élévation transitoire de l'endotoxémie et de sCD14. Ceci était suivi d'un pic significatif de la cytokine pro-inflammatoire IL6 observé deux heures après l'ingestion du repas (Fig. 5) (Laugerette et al., 2011b). De plus, nous avons montré par microscopie électronique et par des mesures d'endotoxémie que les LPS étaient transportés en partie par les chylomicrons. De plus, dans cette même cohorte, huit semaines d'augmentation des apports alimentaires $(+760 \mathrm{kcal}$ par jour sous forme de beurre, d'amandes et d'emmental) ont abouti à $60 \%$ d'augmentation de cette endotoxémie post-prandiale suite au même repas test (Laugerette et al., 2014). Chez le rat, nous avons mis en évidence qu'un gavage avec une émulsion (huile

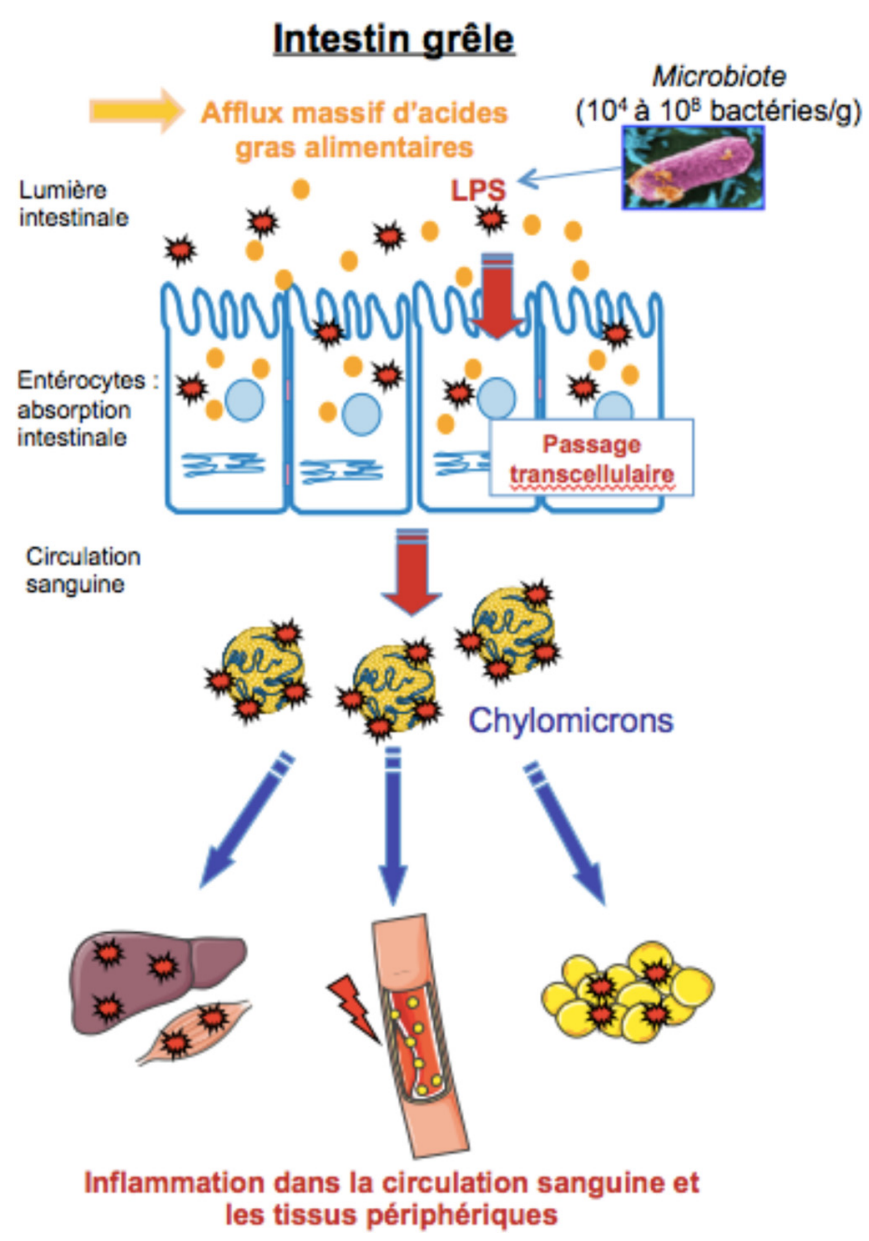

Fig. 4. Endotoxémie post-prandiale et inflammation associée suite au passage transcellulaire intestinal de lipopolysaccharides (LPS) bactériens. Lors d'un afflux d'acides gras en phase post-prandiale, les LPS du microbiote intestinal peuvent être absorbés à la faveur d'un passage transcellulaire au cours de l'absorption intestinale des lipides, puis être transportés dans la circulation sanguine via les chylomicrons sécrétés. Les LPS circulants sont alors en partie pris en charge par les transporteurs spécifiques décrits sur la Figure 3, pouvant ainsi générer une réaction inflammatoire dans l'endothélium vasculaire et les tissus périphériques. Source : adapté de Vors et al. (2014).

de tournesol et lécithine) augmentait l'endotoxémie contrairement à un gavage avec la même huile non émulsionnée, l'accumulation post-prandiale des endotoxines étant corrélée positivement avec celle des triglycérides suite à ces différentes charges en lipides (Fig. 6) (Laugerette et al., 2011b). Chez l'homme, d'autres études confirment ce phénomène d'endotoxémie post-prandiale chez des diabétiques de type 2 (Harte et al., 2012) et chez des obèses morbides (Clemente-Postigo et al., 2012). Plus récemment, nous avons montré qu'une augmentation de la quantité de matière grasse de $10 \mathrm{~g}$ à $40 \mathrm{~g}$ dans un petit-déjeuner réaliste (matière grasse laitière, pain et lait écrémé) induit une endotoxémie post-prandiale cumulée similaire chez l'homme normopondéré. En revanche, chez des hommes obèses non diabétiques, le repas contenant $40 \mathrm{~g}$ de matière grasse induit une endotoxémie post-prandiale cumulée plus élevée qu'avec $10 \mathrm{~g}$ de matière grasse. Ceci est associé à 


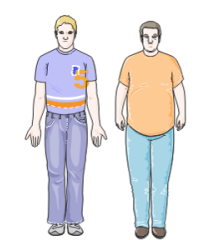

Hommes jeunes sains, normopondérés à surpoids

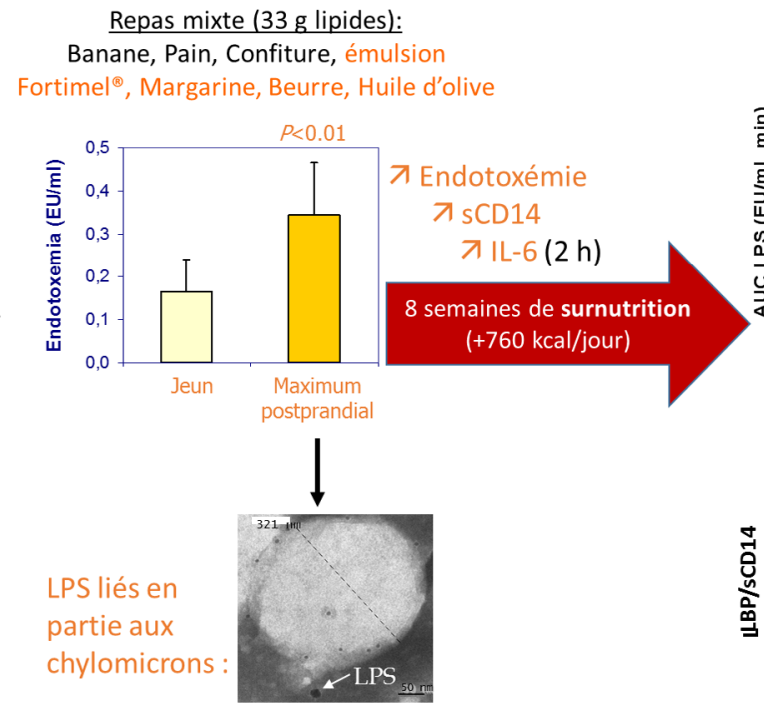

Même repas mixte (33 g lipides):
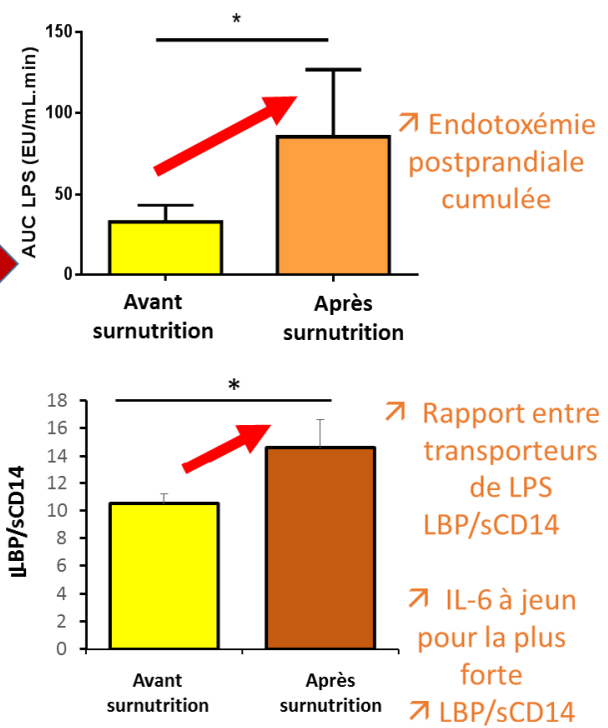

Fig. 5. Résumé des études récentes sur l'endotoxémie post-prandiale avant et après une surnutrition chez l'homme (Laugerette et al., 2011a, 2011b, 2014). Des jeunes hommes de poids normal ou en surpoids ont été soumis au même test d'exploration post-prandiale avant et après huit semaines de surnutrition.

un enrichissement supérieur en LPS des chylomicrons au cours de la phase post-prandiale chez les sujets obèses, comparativement aux sujets normopondérés (Vors et al., 2015). Ainsi, nos travaux montrent que l'endotoxémie postprandiale est modulée par la quantité de matière grasse ingérée chez l'homme obèse, en partie via une prise en charge différente des LPS dans la circulation sanguine via les chylomicrons (Fig. 7).

\subsection{L'endotoxémie métabolique peut être modifiée par le type de matière grasse chez la souris}

L'ensemble des résultats précédents a mis en évidence que les régimes alimentaires déséquilibrés et notamment riches en lipides entraînent une augmentation de l'endotoxémie, notamment via les phases post-prandiales successives, qui peut contribuer au développement et au maintien de l'inflammation à bas-bruit. Nous avons ensuite cherché à savoir si la composition des matières grasses ingérées pouvait influencer l'endotoxémie. De plus, la plupart des études réalisées chez les rongeurs utilisent des régimes dont l'apport énergétique fourni par les lipides est supérieur à $60 \%$ et souvent à base de saindoux et dépourvus de glucides (Cani et al., 2007). Nous avons donc effectué une étude pour comparer les effets de différentes huiles sur les marqueurs d'endotoxémie et l'inflammation associée. Nous avons soumis des souris pendant huit semaines à quatre régimes hyperlipidiques différents, enrichis en matière grasse laitière, huile de palme (raffinée, non hydrogénée), huile de colza ou huile de tournesol. L'apport énergétique fourni par les lipides dans ces régimes se rapprochait de la réalité des régimes occidentaux, à savoir $\sim 38 \%$ d'énergie apportée par ces derniers (soit $\sim 20 \mathrm{~g} / 100 \mathrm{~g}$ de régime) ; les huiles étant incorporées dans les croquettes d'entretien des souris (principalement à base de céréales et de protéines de soja et de poisson). Nous avons montré que les souris nourries avec le régime enrichi en huile de palme présentaient le taux plasmatique d'IL-6 le plus élevé avec une forte augmentation de l'expression de la cytokine pro-inflammatoire IL-1 $\beta$ et des récepteurs des endotoxines TLR4 et CD14 dans le tissu adipeux (Laugerette et al., 2012). Cette inflammation plus importante dans ce groupe était associée à une proportion augmentée d'Escherichia coli dans le microbiote et fortement corrélée avec la proportion relative des transporteurs plasmatiques des endotoxines. En particulier, le rapport LBP/sCD14 était plus élevé dans ce groupe ayant développé une inflammation métabolique, par rapport aux autres groupes n'ayant pas développé d'inflammation (Fig. 6). Or, ce rapport entre transporteurs des LPS est connu pour être augmenté lors d'une réponse inflammatoire aiguë (Stoll et al., 2004). Le groupe nourri du régime enrichi en huile de colza présentait quant à lui la concentration plasmatique la plus élevée en sCD14 ainsi qu'une moindre présence de marqueurs inflammatoires dans le plasma. Dans le tissu adipeux également, une moindre expression des marqueurs inflammatoires et des récepteurs aux LPS était observée dans ce groupe. Or, il a été proposé que sCD14 puisse exercer des effets métaboliques bénéfiques dans le contexte de l'insulinorésistance induite par l'inflammation (Fernandez-Real et al., 2011). Ainsi, nos résultats suggèrent qu'un régime enrichi en huile de palme résulte en un transport plus actif et davantage pro-inflammatoire des LPS vers les tissus cibles via un taux élevé de LBP et une plus faible concentration plasmatique de $\mathrm{sCD} 14$. À l'inverse, un régime enrichi avec de l'huile de colza résulte en une moindre inflammation systémique et dans le tissu adipeux, notamment via une augmentation de sCD14 (Laugerette et al., 2012). Nous avons donc établi la preuve de concept que la composition en lipides des régimes alimentaires module différemment leur résultante inflammatoire au travers du métabolisme des endotoxines. 


\section{A}

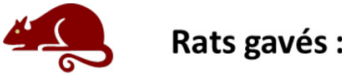

オ Endotoxémie postprandiale cumulée :

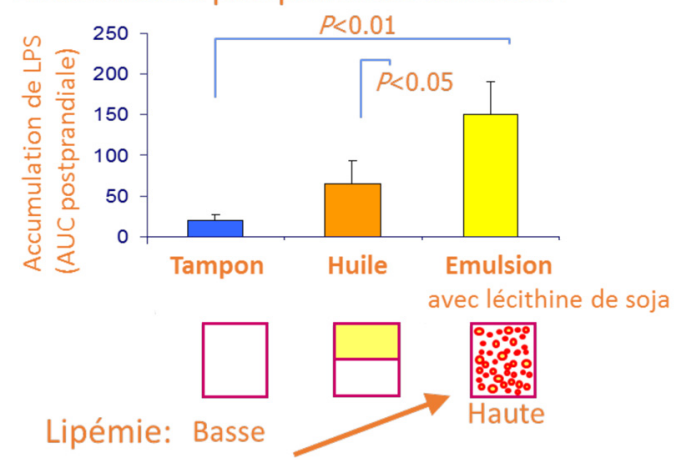

\section{B}

Souris nourries 8 semaines de croquettes d'entretien enrichies à $20 \%$ lipides

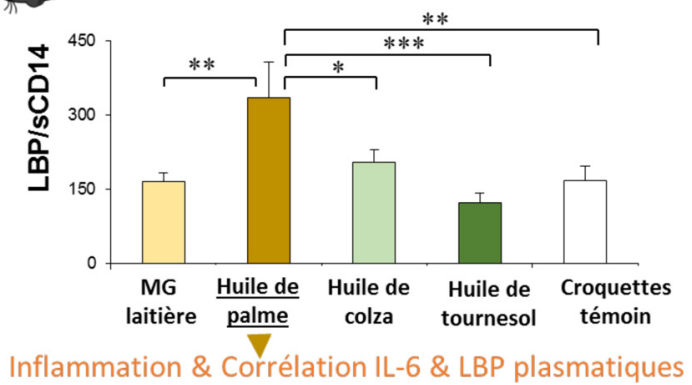

Fig. 6. Résumé des études sur l'impact de la structure émulsionnée et de la composition en huile sur l'endotoxémie et l'inflammation (Laugerette et al., 2011a, 2011b, 2012). A. Des rats cathéterisés ont été gavés avec un tampon, de l'huile de tournesol + le tampon, ou l'huile de tournesol émulsionnée dans le tampon avec des PL de soja (lécithine) ; le plasma a été collecté au cours de la phase postprandiale. B. Des souris ont été nourries de régimes hyperlipidiques contenant $20 \%$ de lipides variant par le type de graisse pendant huit semaines ; différents marqueurs d'endotoxémie et d'inflammation ont été mesurés dans le plasma et le tissu adipeux.

\section{Impact métabolique de l'absorption des lipides et des endotoxines : les lipides polaires émulsifiants modulent ces phénomènes}

Dans les produits manufacturés, la structure émulsionnée des huiles et des matières grasses est due à la présence ou à l'ajout de composés synthétiques tels que les dérivés de polyoxyéthène (polysorbate 80 [PS80]) ou de composés semisynthétiques tels que les dérivés de cellulose (carboxymethylcellulose [CMC]) et les mono- et diglycérides d'acides gras ou encore de composés naturels qui peuvent être de nature protéique (caséinates) et/ou lipidique (phospholipides/lipides polaires). La principale source commerciale de lipides polaires est actuellement la lécithine de soja (Burling et al., 2009). La controverse autour de la suprématie de ce dernier ingrédient en termes notamment de développement durable encourage une diversification des sources de lipides polaires émulsifiants dans les aliments. De plus, certains émulsifiants synthétiques ou semi-synthétiques comme le PS80 et la CMC favoriseraient les maladies inflammatoires intestinales et l'insulinorésistance chez la souris en exerçant un effet détergent dans l'intestin qui altèrerait la fonction de barrière intestinale (Chassaing et al., 2015). Dans ce contexte, les lipides polaires du lait suscitent un intérêt grandissant. Plusieurs études soulignent que ces derniers pourraient exercer des effets bénéfiques dans diverses pathologies dont le cancer colorectal, les désordres neurologiques et les maladies cardiométaboliques (Cohn et al., 2009 ; Castro-Gomez et al., 2015 ; Kullenberg et al., 2012). Nous avons donc cherché à identifier, chez la souris, l'impact de l'utilisation de lipides polaires laitiers en comparaison avec des lipides polaires de soja (lécithine de soja) sur la digestion, l'absorption et le métabolisme post-prandial des lipides lorsqu'ils sont utilisés comme émulsifiant, et à plus long terme incorporés dans un régime hyperlipidique sur le métabolisme lipidique, l'adiposité et l'inflammation du tissu adipeux (Fig. 8).

Chez des souris gavées avec des émulsions d'oléine laitière de tailles de gouttelettes similaires, par comparaison avec les lipides polaires de soja, les lipides polaires laitiers induisent une cinétique de lipémie post-prandiale plus précoce avec des concentrations plasmatiques de triglycérides et d'acides gras libres plus élevées au bout d'une heure, puis moins élevées au bout de quatre heures de digestion. Cette différence de cinétique de lipémie est associée à une modulation de la digestion des lipides, notamment une augmentation de la lipolyse intestinale et des modifications d'expression de gènes du métabolisme lipidique dans l'intestin (Lecomte et al., 2015). De plus, une augmentation de taille des chylomicrons est observée après deux heures de digestion de l'émulsion à base de lipides polaires laitiers et pourrait avoir favorisé leur élimination de la circulation sanguine, expliquant le retour plus rapide de la lipémie à un niveau basal par comparaison à la lécithine de soja (Lecomte et al., 2016). Par ailleurs, après huit semaines d'un régime riche en huile de palme contenant $1,2 \%$ de lipides polaires de soja, une augmentation plus importante de la masse du tissu adipeux blanc est observée en comparaison avec le même régime dépourvu de lipides polaires, avec de plus gros adipocytes (Lecomte et al., 2016) (Fig. 3). De plus, cette prise de masse grasse plus importante n'est pas observée en présence de $1,2 \%$ de lipides polaires laitiers dans le régime hyperlipidique. Compte tenu des résultats de l'étude clinique LIPINFLOX montrant qu'une structure émulsionnée induisant une cinétique de lipémie plus rapide/précoce peut favoriser la $\beta$-oxydation des acides gras au détriment de leur stockage, un tel effet a pu contribuer à limiter l'adiposité au long terme des souris nourries avec des lipides polaires laitiers (Fig. 8). De plus, le tissu adipeux blanc des souris ayant reçu les lipides polaires laitiers présente une moindre expression de CD68, marqueur de l'infiltration macrophagique, en comparaison avec les souris du régime enrichi en lipides polaires de soja et du régime dépourvu de lipides polaires. Nous avons également observé une moindre expression d'adipokines pro-inflammatoires telles que MCP-1, IL-6 ou TNF- $\alpha$ (Lecomte et al., 2016). En parallèle, le régime à base de lipides polaires laitiers induit également une augmentation du nombre de cellules sécrétrices du gel de mucus dans le côlon (Fig. 8). Cet effet peut être dû à l'apparition observée d'une petite quantité d'acides gras saturés spécifiques de la sphingomyéline des lipides polaires laitiers dans les selles (C22:0, C24:0) et suggère une amélioration de la barrière intestinale (Lecomte et al., 2016). Cela pourrait à 


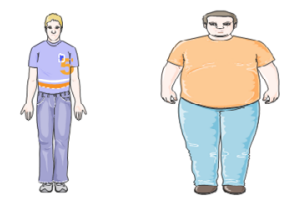

Hommes jeunes normopondérés vs obèses normolipémiques non-diabétiques

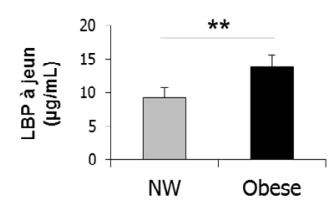

ᄀ LBP à jeun chez l'obèse

Dans la cohorte entière:

Corrélation avec I'IL-6 postprandiale
Repas avec $10 \mathrm{~g}$ ou $40 \mathrm{~g}$ lipides: Pain, Lait écrémé, Matière grasse laitière (MGLA) tartinée
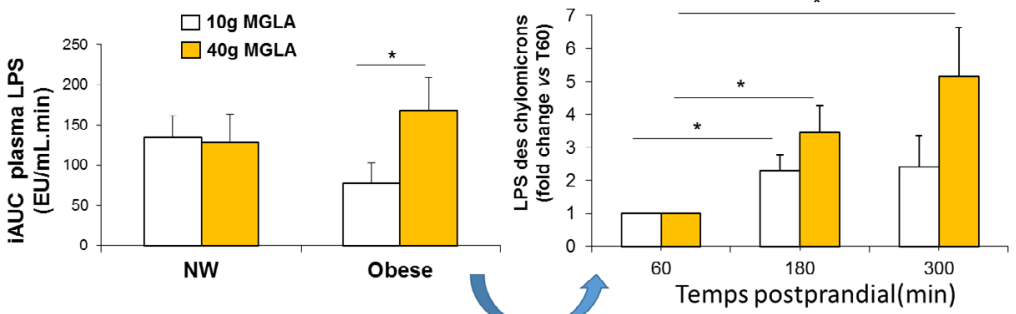

Z Endotoxémie postprandiale cumulée avec la teneur en matière grasse du repas chez l'obèse

Dans la cohorte entière

Corrélation avec la triglycéridémie postprandiale

Fig. 7. Résumé de l'étude sur l'endotoxémie post-prandiale associée aux chylomicrons selon la quantité de matière grasse ingérée chez l'homme normopondéré ou obèse (Vors et al., 2015). Des hommes jeunes normopondérés ou obèses ont été soumis à deux tests d'exploration postprandiale variant par la quantité de matière grasse dans le repas.

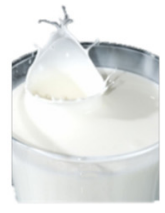

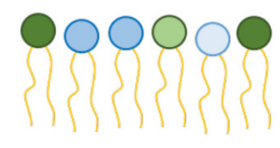

LP laitiers

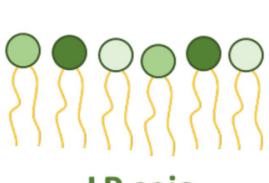

LP soja

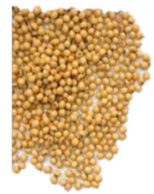

Incorporés dans un régime hyper-lipidique :

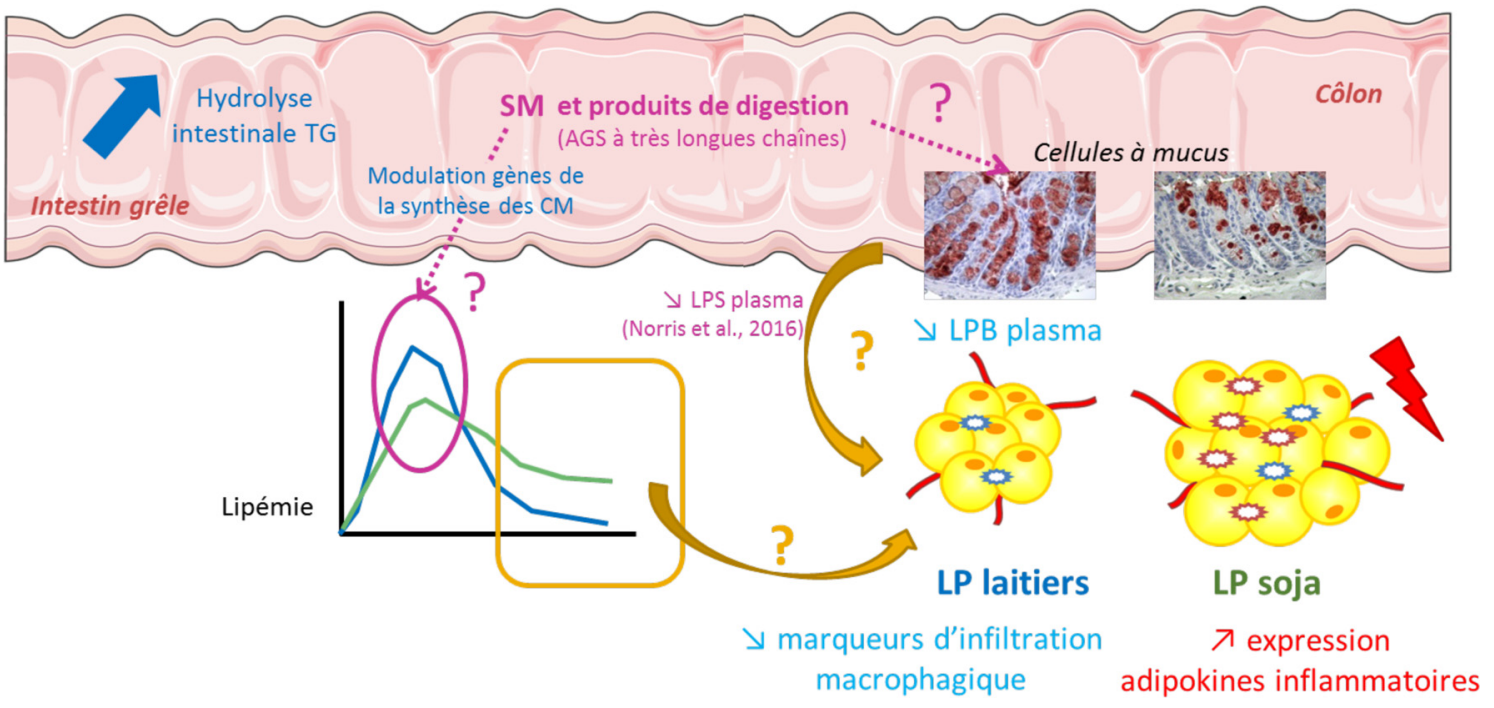

Fig. 8. Résumé des études sur l'impact des lipides polaires laitiers par rapport aux lipides polaires de soja chez la souris (Lecomte et al., 2015, 2016). Dans une première étude, des souris ont été gavées avec une émulsion d'oléine laitière stabilisée soit par des lipides polaires laitiers, soit par des lipides polaires de soja ; les lipides plasmatiques et la digestion ont été mesurés. Dans une deuxième étude, des souris ont été nourries pendant huit semaines avec un régime semi-synthétique hyperlipidique à base d'huile de palme enrichi soit avec des lipides polaires laitiers, soit avec des lipides polaires de soja (1,2\% en remplacement de triglycérides de l'huile du régime). AGS : acides gras saturés ; CM : chylomicrons ; LP : lipides polaires ; SM : sphingomyéline.

terme protéger de l'inflammation métabolique induite notamment par l'absorption d'endotoxines comme expliqué plus haut; une étude récente chez la souris a par ailleurs montré que la sphingomyéline laitière peut contribuer à diminuer l'endotoxémie métabolique suite à un régime hyperlipidique chez la souris (Norris et al., 2016). Dans la poursuite de l'étude du devenir métabolique des lipides, il deviendra ainsi crucial de s'intéresser également aux effets de résidus lipidiques non absorbés au cours de la digestion, atteignant le côlon et y exerçant des effets métaboliques spécifiques. 


\section{Effets de la lécithine de soja dans deux régimes hyper-lipidiques (huiles de lin et de palme)}

\section{Effets spécifiques de la lécithine de soja dans le régime à base d’huile de lin}

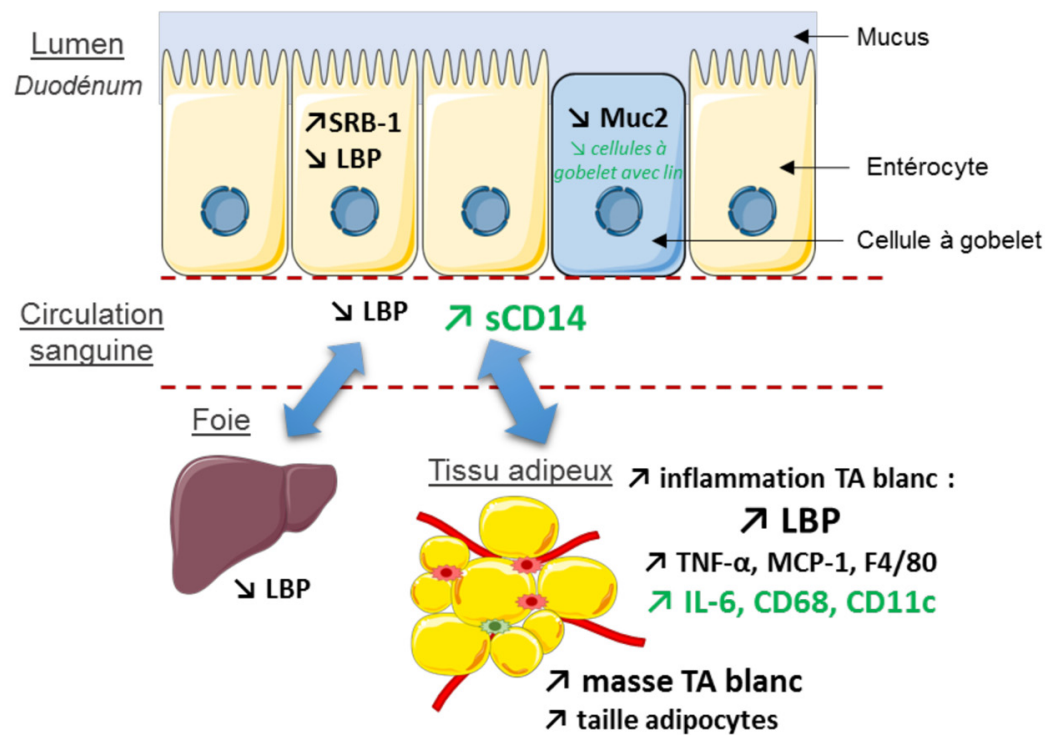

Fig. 9. Résumé de l'étude sur l'impact relatif de la lécithine de soja et du type d'huile dans un régime hyperlipidique chez la souris sur l'endotoxémie et l'inflammation (Lecomte et al., 2017). Des souris ont été nourries pendant huit semaines avec un régime semi-synthétique hyperlipidique à base d'huile de palme ou d'huile de lin, et non enrichi ou enrichi avec des lipides polaires de soja (1,2\% en remplacement de triglycérides de l'huile du régime).

\section{Optimiser l'impact métabolique et anti- inflammatoire des AGPI n-3 par la formulation}

Conformément aux recommandations nutritionnelles de l'Anses, la consommation d'AGPI doit être encouragée pour assurer les apports nécessaires au bon fonctionnement de l'organisme. Cela concerne notamment l'acide gras essentiel alpha-linolénique (ALA, 18:3 n-3), contenu notamment dans les huiles de colza et de lin, et son dérivé le DHA (22:6 n-3), contenu notamment dans les lipides marins ; ALA et DHA présentent des effets hypolipémiants et anti-inflammatoires bien démontrés. Compte tenu des effets observés de la lécithine de soja dans les régimes enrichis en huile de palme, dans une deuxième partie de l'étude ci-dessus, nous avons cherché à savoir si ces effets étaient différents dans un régime hyperlipidique à base d'ALA. Nous avons donc comparé les effets de l'incorporation des $1,2 \%$ de lipides polaires de soja dans le régime hyperlipidique à base d'huile de palme ou dans un régime à base d'huile de lin, riche en ALA. Dans les deux groupes enrichis en lipides polaires de soja, une augmentation de la masse de tissu adipeux blanc a été observée par rapport aux groupes hyperlipidiques dépourvus de lipides polaires, ainsi qu'une induction de MCP-1 et de la LBP (transporteur des endotoxines). Cependant, seul le régime associant l'huile de lin avec les lipides polaires de soja induit une plus forte expression de gènes associés à l'inflammation dans le tissu adipeux et une concentration plasmatique plus élevée en sCD14 (transporteur soluble des endotoxines) (Lecomte et al., 2017). Nous avons ainsi montré dans cette étude que les transporteurs des LPS, LBP et sCD14, et l'inflammation du tissu adipeux peuvent être modulés par les lipides polaires de soja dans des régimes hyperlipidiques de différentes compositions en huiles (Fig. 9). Il est important de souligner que le régime à base d'huile de lin, riche en AGPI n-3 a exercé des effets métaboliques bénéfiques comme attendu, qui ont cependant été supprimés par incorporation de lécithine de soja. Ces premiers résultats montrent l'importance de s'interroger sur l'impact des agents de formulation des lipides dans les émulsions et aliments complexes sur l'impact métabolique des huiles, notamment celles riches en AGPI dont la consommation est encouragée.

Concernant les AGPI n-3 à longue chaîne marins, les formes moléculaires et supramoléculaires d'apport peuvent également en moduler les effets. Les AGPI n-3 sont mieux incorporés dans les lipides hépatiques et plasmatiques chez le rat nourris de liposomes de phospholipides marins plutôt que d'huiles triglycéridiques (Cansell et al., 2003, 2006) bien que l'effet hypotriglycéridémiant exercé après deux semaines de supplémentation soit similaire (Cansell et al., 2006). Concernant des effets métaboliques plus larges, une supplémentation de régimes hyperlipidiques avec une dose nutritionnelle d'AGPI n-3 à longue chaîne sous forme de phospholipides induit des effets majeurs sur le tissu adipeux, notamment une diminution de la taille des adipocytes, qui ne sont pas observés avec une supplémentation sous forme de TAG (Awada et al., 2013). Ces résultats peuvent expliquer en partie les différences d'effets observées chez l'homme entre l'huile de krill, riche en phospholipides, et les huiles de poisson, riches en TAG (Bunea et al., 2004 ; Kidd, 2007 ; Tou et al., 2007). De plus, les supplémentations en huiles de poisson sont le plus souvent réalisées sous forme de capsules d'huile ou bien de gouttelettes d'émulsion incorporées dans une boisson ou un aliment enrichi. L'émulsification de l'huile améliore l'absorption intestinale d'huile de poisson et augmente les concentrations 
plasmatiques en acide eicosapentaénoïque (EPA, 20:5n-3) et DHA chez l'homme par rapport à une huile non émulsionnée (Garaiova et al., 2007 ; Raatz et al., 2009). Des effets de l'émulsification sur une augmentation de l'absorption et de l'accrétion du DHA dans différents tissus ont été observés chez le rat (Dey et al., 2012 ; Sugasini et Lokesh, 2013). Cependant, compte tenu des résultats récents sur l'augmentation de la $\beta$-oxydation des acides gras ingérés lorsque la matière grasse laitière est administrée sous forme émulsionnée (Vors et al., 2013), il est aujourd'hui important de vérifier si l'émulsification de l'huile de poisson ne pourrait pas résulter en une $\beta$-oxydation des AGPI n-3 de manière à optimiser leurs bénéfices métaboliques. De plus, la composition des émulsions d'huiles de poisson et notamment le type d'agent émulsifiant peut aussi avoir des conséquences sur la peroxydation des AGPI d'intérêt en conditions digestives (Kenmogne-Domguia et al., 2014). Or, certains composés finaux de peroxydation des AGPI, tels les 4-hydroxyalcénals (4-HHE pour la série des AGPI n-3), peuvent être absorbés dans l'intestin et générer un stress oxydant et une inflammation métabolique et intestinale (Awada et al., 2012). Il convient donc de chercher à optimiser les formes d'apport des AGPI n-3 en émulsion pour en limiter l'oxydation et optimiser leurs effets bénéfiques, notamment sur le métabolisme lipidique et l'inflammation.

\section{Conclusion et perspectives}

Si la diversité des structures lipidiques dans les aliments est désormais bien connue et décrite, l'effet de ces structures sur la digestion des lipides et la libération des acides gras dans le tractus digestif est de plus en plus documenté notamment par l'apport des études in vitro. Des études récentes montrent que la structure émulsionnée notamment peut contribuer aux effets des acides gras sur l'organisme en modulant leur devenir métabolique. Cela nous a amené à proposer le concept de « lipides rapides/lipides lents » pour la modulation de l'utilisation métabolique des acides gras par la structuration de la matière grasse dans l'aliment (Fig. 2).

D'après une enquête de l'Insee publiée en 2012, les Français privilégient désormais les plats préparés aux produits frais (Nabli et al., 2012). En outre, on retrouve parmi les principaux contributeurs de la consommation en acides gras saturés, la catégorie des " pâtisserie et gâteaux » et parmi les principaux contributeurs de la consommation en AGPI, celles des « condiments et sauces » et «plats composés » (TressouCosmao et al., 2015). Ces trois catégories regroupent des produits formulés, fortement susceptibles de contenir des huiles et graisses émulsionnées et différents agents émulsifiants. Cela renforce ainsi l'intérêt de mieux connaître l'effet métabolique des structures émulsionnées et des agents émulsifiants retrouvés dans ces produits.

Par ailleurs, nos travaux récents montrent que tous les émulsifiants naturels ne semblent pas avoir des effets métaboliques similaires. Cela incite donc à poursuivre l'étude des effets des émulsifiants et notamment de différentes sources de lipides polaires chez l'homme, en particulier dans le contexte du développement de stratégies nutritionnelles capables de limiter ou de prévenir les désordres métaboliques associés aux états d'obésité. De plus, la relation entre les régimes obésogènes et l'endotoxémie est un nouveau concept contribuant à expliquer le développement et le maintien d'un état inflammatoire sub-clinique. Plusieurs études, dont les nôtres, appuient l'idée que la digestion d'un repas riche en lipides augmente l'absorption des endotoxines présentes dans le tractus gastro-intestinal, dont le devenir va ensuite dépendre de leur prise en charge par différents types de transporteurs. Les conséquences à long terme de cette endotoxémie postprandiale, se répétant repas après repas, doivent encore être élucidées. Cependant, nos travaux permettent d'envisager qu'en modulant la quantité, la composition et/ou la structure des lipides alimentaires, des stratégies nutritionnelles puissent être mises en place pour limiter ces phénomènes dans le but de contribuer à prévenir l'inflammation à bas-bruit caractéristique des maladies métaboliques. Ainsi, la compréhension du rôle des différentes sources de lipides dans le maintien d'une bonne santé passera, dans les années à venir, par l'étude approfondie du devenir métabolique des lipides alimentaires en fonction des aliments, des repas, de l'équilibre global des régimes alimentaires et, sans doute aussi, des rythmes de consommation.

Remerciements. Nous remercions chaleureusement l'ensemble de nos collègues du laboratoire CarMeN, du CRNH RhôneAlpes et partenaires ayant contribué et/ou étant coauteurs de nos publications citées dans cet article. Nous remercions plus particulièrement certains collègues également auteurs d'articles dans le présent numéro avec lesquels nous avons collaboré dans les travaux et articles détaillés dans cette revue : Claude Genot et Anne Meynier (Inra, collaboration sur l'impact des vecteurs et de la peroxydation des AGPI n-3 dans le cadre du projet AGECANINOX, ANR-08-ALIA-002, coord. C. Genot, 2009-2012) ; Frédéric Carrière (CNRS), Leslie Couedelo et Carole Vaysse (ITERG) (collaboration sur l'impact des agents émulsifiants sur la digestion et l'absorption intestinale in vitro et chez le rat, dans le cadre de projets au sein de l'Institut Carnot LISA, ANR-07-CARN-009-01), et Claire Bourlieu (Inra, collaboration sur l'impact des lipides polaires du lait ou du soja sur la digestion et l'absorption in vitro et in vivo, dans le cadre du projet VALOBAB, ANR11-ALID-007, 2012-2016, coord. M.C. Michalski).

Le laboratoire CarMeN et l'ITERG sont membres de l'UMT ACTIA BALI (Biodisponibilité des lipides et intestin).

Cécile Vors remercie l'Inra et le CNIEL pour le financement de sa thèse. C.V. a reçu un prix de recherche de la Fondation Nestlé France. Manon Lecomte remercie la région RhôneAlpes ARC1 pour sa bourse doctorale. Marie-Caroline Michalski et Fabienne Laugerette remercient l'Institut Carnot LISA, la Société francophone du diabète et la Société francophone de nutrition. M.C.M. remercie le CNIEL pour le financement de l'étude clinique LIPINFLOX. Les financeurs n'ont eu aucun rôle dans la réalisation de l'étude, l'analyse des données ni la décision de publier.

Déclaration de conflits d'intérêt. Marie-Caroline Michalski a coordonné un projet visant à valoriser les propriétés nutritionnelles des lipides polaires laitiers contenus dans le babeurre, financé par l'ANR sous la référence ANR-11-ALID007-01 (VALOBAB), auquel Cécile Vors, Manon Lecomte et Fabienne Laugerette ont participé. Marie-Caroline Michalski a reçu des financements de projets de recherche partenariaux avec le CNIEL, Nutricia Research, et Sodiaal-Candia R\&D 
et exerce des activités de consultance pour des entreprises de l'agroalimentaire. M.C.M. et C.V. ont été rémunérées par le CNIEL pour réaliser un travail de revue bibliographique sur les produits laitiers et l'inflammation métabolique (Vors et al., 2014).

\section{Références}

Amar J, Burcelin R, Ruidavets JB, et al. 2008. Energy intake is associated with endotoxemia in apparently healthy men. $\mathrm{Am} \mathrm{J}$ Clin Nutr 87 (5): 1219-1223.

Armand M, Pasquier B, Andre M, et al. 1999. Digestion and absorption of 2 fat emulsions with different droplet sizes in the human digestive tract. Am J Clin Nutr 70 (6): 1096-1106.

Awada M, Meynier A, Soulage CO, et al. 2012. Dietary oxidized n-3 PUFA induce oxidative stress and inflammation: role of intestinal absorption of 4-HHE and reactivity in intestinal cells. J Lipid Res 53 (10): 2069-2080.

Awada M, Soulage CO, Meynier A, et al. 2013. n-3 PUFA added to high-fat diets affect differently adiposity and inflammation when carried by phospholipids or triacylglycerols in mice. Nutr Metab (Lond) 10 (1): 23.

Bazil V, Strominger JL. 1991. Shedding as a mechanism of downmodulation of CD14 on stimulated human monocytes. J Immunol 147 (5): 1567-1574.

Bourlieu C, Michalski MC. 2015. Structure-function relationship of the milk fat globule. Curr Opin Clin Nutr Metab Care 18 (2): $118-127$.

Bunea R, El Farrah K, Deutsch L. 2004. Evaluation of the effects of Neptune Krill Oil on the clinical course of hyperlipidemia. Altern Med Rev 9 (4): 420-428.

Burling H, Nilsson A, Ohlsson L. 2009. Milk phospholipids, a new ingredient for formulation of functional foods with bioactivity. Inform 20 (8): 494-496.

Cani PD, Amar J, Iglesias MA, et al. 2007. Metabolic endotoxemia initiates obesity and insulin resistance. Diabetes 56 (7): 17611772.

Cani PD, Bibiloni R, Knauf C, et al. 2008. Changes in gut microbiota control metabolic endotoxemia-induced inflammation in high-fat dietinduced obesity and diabetes in mice. Diabetes 57 (6): 1470-1481.

Cansell M, Nacka F, Combe N. 2003. Marine lipid-based liposomes increase in vivo FA bioavailability. Lipids 38 (5): 551-559.

Cansell M, Moussaoui N, Petit AP, et al. 2006. Feeding rats with liposomes or fish oil differently affects their lipid metabolism. Eur J Lipid Sci Technol 108: 459-467.

Castro-Gomez P, Garcia-Serrano A, Visioli F, et al. 2015. Relevance of dietary glycerophospholipids and sphingolipids to human health. Prostaglandins Leukot Essent Fatty Acids 101: 41-51.

Chassaing B, Koren O, Goodrich JK, et al. 2015. Dietary emulsifiers impact the mouse gut microbiota promoting colitis and metabolic syndrome. Nature 519 (7541): 92-96.

Clemente-Postigo M, Queipo-Ortuno MI, Murri M, et al. 2012. Endotoxin increase after fat overload is related to postprandial hypertriglyceridemia in morbidly obese patients. J Lipid Res 53 (5): 973-978.

Cohn J, Tandy S, Wat E, et al. 2009. Dietary milk phospholipid as a cardiovascular nutraceutical. Atheroscler Suppl 10: 2.

Couëdelo L, Boue-Vaysse C, Fonseca L, et al. 2011. Lymphatic absorption of alpha-linolenic acid in rats fed flaxseed oil-based emulsion. Br J Nutr 105 (7): 1026-1035.

Couëdelo L, Amara S, Lecomte M, et al. 2015. Impact of various emulsifiers on ALA bioavailability and chylomicron synthesis through changes in gastrointestinal lipolysis. Food Funct 6 (5): 1726-1735.

Creely SJ, McTernan PG, Kusminski CM, et al. 2007. Lipopolysaccharide activates an innate immune system response in human adipose tissue in obesity and type 2 diabetes. Am $J$ Physiol Endocrinol Metab 292 (3): E740-E747.

Deopurkar R, Ghanim H, Friedman J, et al. 2010. Differential effects of cream, glucose, and orange juice on inflammation, endotoxin, and the expression of Toll-like receptor- 4 and suppressor of cytokine signaling-3. Diabetes Care 33 (5): 991-997.

Dey TK, Ghosh S, Ghosh M, et al. 2012. Comparative study of gastrointestinal absorption of EPA \& DHA rich fish oil from nano and conventional emulsion formulation in rats. Food Res Int 49 (1): 72-79.

Eichbaum EB, Harris HW, Kane JP, et al. 1991. Chylomicrons can inhibit endotoxin activity in vitro. J Surg Res 51 (5): 413-416.

Erridge C, Attina T, Spickett CM, et al. 2007. A high-fat meal induces low-grade endotoxemia: evidence of a novel mechanism of postprandial inflammation. Am J Clin Nutr 86 (5): 1286-1292.

Fernandez-Real JM, Perez del Pulgar S, Luche E, et al. 2011. CD14 modulates inflammation-driven insulin resistance. Diabetes 60 (8): 2179-2186.

Gallay P, Barras C, Tobias PS, et al. 1994. Lipopolysaccharide (LPS)binding protein in human serum determines the tumor necrosis factor response of monocytes to LPS. J Infect Dis 170 (5): 1319-1322.

Garaiova I, Guschina I, Plummer SF, et al. 2007. A randomised crossover trial in healthy adults indicating improved absorption of omega-3 fatty acids by pre-emulsification. Nutr $J 6$ (1): 4 .

Gautier T, Klein A, et al. 2008. Effect of plasma phospholipid transfer protein deficiency on lethal endotoxemia in mice. J Biol Chem 283 (27): 18702-18710.

Genot C, Meynier A, et al. 2016. Bioavailability of lipids in fish and fish oils. In: Raatz SK, Bibus DM, eds. Fish and fish oil in health and disease prevention. London: Academic Press.

Ghanim H, Sia CL, et al. 2010. Orange juice neutralizes the proinflammatory effect of a high-fat, high-carbohydrate meal and prevents endotoxin increase and Toll-like receptor expression. Am J Clin Nutr 91 (4): 940-949.

Ghoshal S, Witta J, et al. 2009. Chylomicrons promote intestinal absorption of lipopolysaccharides. J Lipid Res 50 (1): 90-97.

Hailman E, Lichenstein HS, et al. 1994. Lipopolysaccharide (LPS)binding protein accelerates the binding of LPS to CD14. $J$ Exp Med 179 (1): 269-277.

Harris HW, Grunfeld C, et al. 1993. Chylomicrons alter the fate of endotoxin, decreasing tumor necrosis factor release and preventing death. J Clin Invest 91 (3): 1028-1034.

Harris HW, Rockey DC, et al. 1998. Chylomicrons alter the hepatic distribution and cellular response to endotoxin in rats. Hepatology 27 (5): 1341-1348.

Harte AL, Varma MC, et al. 2012. High fat intake leads to acute postprandial exposure to circulating endotoxin in type 2 diabetic subjects. Diabetes Care 35 (2): 375-382.

Hiki N, Berger D, et al. 1999. Changes in endotoxin-binding proteins during major elective surgery: Important role for soluble CD14 in regulation of biological activity of systemic endotoxin. Clin Diagn Lab Immunol 6 (6): 844-850.

Kenmogne-Domguia HB, Moisan S, et al. 2014. The initial characteristics of marine oil emulsions and the composition of the media inflect lipid oxidation during in vitro gastrointestinal digestion. Food Chem 152: 146-154.

Keogh JB, Wooster TJ, et al. 2011. Slowly and rapidly digested fat emulsions are equally satiating but their triglycerides are differentially absorbed and metabolized in humans. JNutr 141 (5): 809-815. 
Kidd PM. 2007. Omega-3 DHA and EPA for cognition, behavior, and mood: clinical findings and structural-functional synergies with cell membrane phospholipids. Altern Med Rev 12 (3): 207-227.

Kullenberg D, Taylor LA, et al. 2012. Health effects of dietary phospholipids. Lipids Health Dis 11: 3.

Lakatos PL, Kiss LS, et al. 2011. Serum lipopolysaccharide-binding protein and soluble CD14 are markers of disease activity in patients with Crohn's disease. Inflamm Bowel Dis 17 (3): 767-777.

Langsted A, Nordestgaard BG. 2015. Nonfasting lipid profiles: the way of the future. Clin Chem 61 (9): 1123-1125.

Lassenius MI, Pietilainen KH, et al. 2011. Bacterial endotoxin activity in human serum is associated with dyslipidemia, insulin resistance, obesity, and chronic inflammation. Diabetes Care 34 (8): 1809-1815.

Laugerette F, Vors C, et al. 2011a. Emulsified lipids increase endotoxemia: possible role in early postprandial low-grade inflammation. $J$ Nutr Biochem 22: 53-59.

Laugerette F, Vors C, et al. 2011b. Complex links between dietary lipids, endogenous endotoxins and metabolic inflammation. Biochimie 93 (1): 39-45.

Laugerette F., Furet JP, et al. 2012. Oil composition of high dat diet affects differently metabolic inflammation in connexion with endotoxin receptors in mice. Am J Physiol Endocrinol Metab 302: E374-E386.

Laugerette F, Alligier M, et al. 2014. Overfeeding increases postprandial endotoxemia in men: Inflammatory outcome may depend on LPS transporters LBP and sCD14. Mol Nutr Food Res 58 (7): 1513-1518.

Laville M, Vors C, Nazare JA, Michalski MC. 2013. Intérêt de la phase postprandiale pour la santé de l'Homme. Bull Acad Natl Med 197(1): 65-77.

Lecomte M, Bourlieu C, et al. 2015. Milk polar lipids affect in vitro digestive lipolysis and postprandial lipid metabolism in mice. J Nutr 145 (8): 1770-1777.

Lecomte M, Couëdelo L, et al. 2016. Dietary emulsifiers from milk and soybean differently impact adiposity and inflammation in association with modulation of colonic goblet cells in high-fat fed mice. Mol Nutr Food Res 60 (3): 609-620.

Lecomte M, Couëdelo L, et al. 2017. Soybean polar lipids differently impact adipose tissue inflammation and the endotoxin transporters LBP and SCD14 in flaxseed vs palm oil-rich diets. $J$ Nutr Biochem 43: 116-124.

Libby P. 2002. Inflammation in atherosclerosis. Nature 420: 868-874.

Matsushita H, Ohta S, et al. 2010. Endotoxin tolerance attenuates airway allergic inflammation in model mice by suppression of the T-cell stimulatory effect of dendritic cells. Int Immunol 22 (9): 739-747.

Michalski MC. 2009. Specific molecular and colloidal structures of milk fat affecting lipolysis, absorption and postprandial lipemia. Eur J Lipid Sci Technol 111 (5): 413-431.

Michalski MC, Vors C. 2013. Impact de la matrice laitière sur le devenir des acides gras. Cholédoc 138 (11-12): 1-6.

Michalski MC, Briard V, et al. 2005. The dispersion state of milk fat influences triglyceride metabolism in the rat $-\mathrm{A}\left(\mathrm{CO}_{2}\right)-\mathrm{C}-13$ breath test study. Eur J Nutr 44 (7): 436-444.

Michalski MC, Soares AF, et al. 2006. The supramolecular structure of milk fat influences plasma triacylglycerols and fatty acid profile in the rat. Eur J Nutr 45 (4): 215-224.
Michalski MC, Genot C, et al. 2013. Multiscale structures of lipids in foods as parameters affecting fatty acid bioavailability and lipid metabolism. Prog Lipid Res 52 (4): 354-373.

Michalski MC, Vors C, et al. 2016. Dietary lipid emulsions and endotoxemia. OCL Oils Fat Crop Lipid 23: 3.

Nabli F, Ricroch L. 2012. Enquête Emploi du temps 2009-2010. INSEE Résultats (130), société. Disponible sur http://www.insee. $\mathrm{fr} / \mathrm{fr} /$ publications-et-services/.

Nordestgaard BG, Benn M, et al. 2007. Nonfasting triglycerides and risk of myocardial infarction, ischemic heart disease, and death in men and women. JAMA 298 (3): 299-308.

Norris GH, Jiang C, et al. 2016. Milk sphingomyelin improves lipid metabolism and alters gut microbiota in high fat diet-fed mice. $J$ Nutr Biochem 30: 93-101.

Osborn MJ, Rosen SM, et al. 1964. Lipopolysaccharide of the Gramnegative cell wall. Science 145: 783-789.

Pastor Rojo O, Lopez San Roman A, et al. 2007. Serum lipopolysaccharide-binding protein in endotoxemic patients with inflammatory bowel disease. Inflamm Bowel Dis 13 (3): 269-277.

Raatz SK, Redmon JB, et al. 2009. Enhanced absorption of n-3 fatty acids from emulsified compared with encapsulated fish oil. $\mathrm{J} \mathrm{Am}$ Diet Assoc 109 (6): 1076-1081.

Raynal-Ljutovak K, Bouvier J, et al. 2011. Organisation structurale et moléculaire des lipides dans les aliments : impacts possibles sur leur digestion et leur assimilation par l'homme. OCL 18 (6): 324-351.

Ross R. 1999. Atherosclerosis is an inflammatory disease. Am Heart $J$ 138 (5 Pt 2): S419-S420.

Stoll LL, Denning GM, et al. 2004. Regulation of endotoxin-induced proinflammatory activation in human coronary artery cells: expression of functional membrane-bound CD14 by human coronary artery smooth muscle cells. J Immunol 173 (2): 13361343.

Sugasini D, Lokesh BR. 2013. Enhanced incorporation of docosahexaenoic acid in serum, heart, and brain of rats given microemulsions of fish oil. Mol Cell Biochem 382 (1-2): 203-216.

Tou JC, Jaczynski J, et al. 2007. Krill for human consumption: nutritional value and potential health benefits. Nutr Rev 65 (2): 63-77.

Tressou-Cosmao J, Pasteau S, Le Guillou C, Simon N. 2015. Analyse des apports nutritionnels en acides gras de la population française à partir des données INCA 2. Rapport ONIDOL-Terres Univia février 2015. Disponible sur www.huilesplaisiretsante.com, mis à jour septembre 2015.

Vors C, Pineau G, et al. 2013. Modulating absorption and postprandial handling of dietary fatty acids by structuring fat in the meal: a randomized crossover clinical trial. Am J Clin Nutr 97 (1): 23-36.

Vors C, Gayet-Boyer C, et al. 2014. Produits laitiers et inflammation métabolique : quels liens en phase postprandiale et à long terme ? Cah Nutr Diet 50 (1): 25-38.

Vors C, Pineau G, et al. 2015. Postprandial endotoxemia linked with chylomicrons and lipopolysaccharides handling in obese versus lean men: a lipid dose-effect trial. J Clin Endocrinol Metab 100 (9): 3427-3435.

Vors C, Lecomte M, et al. 2016. Impact de la structure émulsionnée des lipides sur le devenir métabolique des acides gras alimentaires. Cah Nutr Diet 51 (5): 238-247.

Vreugdenhil AC, Rousseau CH, et al. 2003. Lipopolysaccharide (LPS)-binding protein mediates LPS detoxification by chylomicrons. J Immunol 170 (3): 1399-1405.

Citation de l'article : Michalski M-C, Vors C, Lecomte M, Laugerette F. 2017. Impacts métaboliques et inflammatoires des matières grasses émulsionnées. OCL 24(2): D203. 